Technological University Dublin

DÜBLIN

ARROW@TU Dublin

\title{
A Novel Processing Route for the Production of Nanoparticulate Zinc Oxide Using an Isophthalate Precursor
}

\author{
Grainne Duffy \\ Declan Mccormack \\ Technological University Dublin, Declan.mccormack@tudublin.ie \\ Suresh Pillai \\ Technological University Dublin, suresh.pillai@tudublin.ie
}

Follow this and additional works at: https://arrow.tudublin.ie/cenresart

Part of the Chemistry Commons

\section{Recommended Citation \\ Duffy, G.M., Pillai, S.C., McCormack, D.E. (2007) 'A novel processing route for the production of nanoparticulate zinc oxide using an isophthalate precursor', Smart Material and Structures, 16 (2007) 1379-1381. doi:10.1088/0964-1726/16/4/052}

This Article is brought to you for free and open access by the Crest: Centre for Research in Engineering Surface Technology at ARROW@TU Dublin. It has been accepted for inclusion in Articles by an authorized administrator of ARROW@TU Dublin. For more information, please contact arrow.admin@tudublin.ie, aisling.coyne@tudublin.ie,gerard.connolly@tudublin.ie. Funder: El 


\title{
A novel processing route for the production of nanoparticulate zinc oxide using an isophthalate precursor
}

\author{
Gráinne M Duffy ${ }^{1}$, Suresh C Pillai ${ }^{2}$ and Declan E McCormack ${ }^{1}$ \\ ${ }^{1}$ School of Chemical and Pharmaceutical Sciences, Dublin Institute of Technology, Dublin 8, \\ Republic of Ireland \\ ${ }^{2}$ Centre for Research in Engineering Surface Technology (CREST), FOCAS Institute, Dublin \\ Institute of Technology, Camden Row, Dublin 8, Republic of Ireland \\ E-mail: suresh.pillai@dit.ie and declan.mccormack@dit.ie
}

Received 1 October 2006, in final form 4 April 2007

Published 13 July 2007

Online at stacks.iop.org/SMS/16/1379

\begin{abstract}
Zinc oxide nanoparticles have been processed from a novel isophthalate precursor. In contrast to those processed from an oxalate precursor, this material exhibits three-dimensional, non-directional aggregation behaviour. Such non-directional aggregation of uniaxial crystallites may allow for the production of structures with a higher proportion of catalytically active surfaces than can be prepared through conventional sol-gel methods. XRD, FTIR, TEM and SEM were used to characterize the synthesized materials. Zinc oxide particles synthesized by using isophthalic acid $\left(\mathrm{C}_{6} \mathrm{H}_{4}-1,3-(\mathrm{COOH})_{2}\right)$ are found to be slightly smaller than the previously reported materials prepared through chelation with oxalic acid $\left(\mathrm{H}_{2} \mathrm{C}_{2} \mathrm{O}_{2} \cdot 2 \mathrm{H}_{2} \mathrm{O}\right)$.
\end{abstract}

\section{Introduction}

Zinc oxide is a wide, direct bandgap semiconductor which has been used in areas such as catalysis [1, 2], gas sensing [3], varistors $[4,5]$, as a piezoelectric actuator [6], and as a transparent conducting oxide layer for solar cell applications [7, 8]. While numerous methods of synthesis of zinc oxide films and structures have been investigated, the sol-gel route is favourable because of its low cost and the non-destructive nature of the processing conditions involved. The number of synthesis methods reported illustrates the ease with which zinc oxide can be made, and controlling the size and shape presents a challenge. Sol-gel methods [4, 5, 9], especially those involving polymeric precursors [10, 11], are of interest in the present work. We have examined the structure and morphology of zinc oxide nanoparticles produced by the calcination of a zinc isophthalate precursor, synthesized in a simple, low temperature reaction. The effect of the chelating agent and solvent have been investigated for this route [12, 13], and indeed previous authors have reported on the characterization of a zinc isophthalate precursor [14]. However, as far as we are aware, the use of isophthalic acid for the production of zinc oxide nanoparticles has not been reported. The solution-phase reaction of zinc acetate and isophthalic acid, in ratios of 1:1 and 1:2, was examined. After a brief ageing period, during which gelation occurred, the precursor powders were calcined to 500 , and $800^{\circ} \mathrm{C}$, and their structure and morphology examined using XRD, FT-IR, SEM and TEM. The product powders were found to be composed of single crystalline aggregates, with a characteristic structure.

\section{Experimental details}

Zinc acetate dihydrate $\left(\mathrm{Zn}\left(\mathrm{CH}_{3} \mathrm{CO}_{2}\right)_{2} \cdot 2 \mathrm{H}_{2} \mathrm{O}, \geqslant 98 \%\right.$, SigmaAldrich), isophthalic acid $\left(\mathrm{C}_{6} \mathrm{H}_{4}-1,3-(\mathrm{COOH})_{2}, 98 \%\right.$, Fluka) and absolute ethanol $\left(\mathrm{C}_{2} \mathrm{H}_{5} \mathrm{OH}\right.$, spectroscopic grade, $>99.5 \%$, Sigma) were used without further purification. Stock solutions containing $1 \mathrm{mmol}$ zinc acetate dihydrate, and the required quantity of isophthalic acid, in $10 \mathrm{ml}$ ethanol, were rapidly combined under stirring. The resultant solution was stirred at room temperature for a further $30 \mathrm{~min}$, then dried in an oven at $100{ }^{\circ} \mathrm{C}$ for $1 \mathrm{~h}$. The powders were then ground and calcined in a muffle furnace at a ramp rate of $10^{\circ} \mathrm{C} \mathrm{min}^{-1}$ and dwell time of $2 \mathrm{~h}$. Powder diffraction measurements were undertaken 


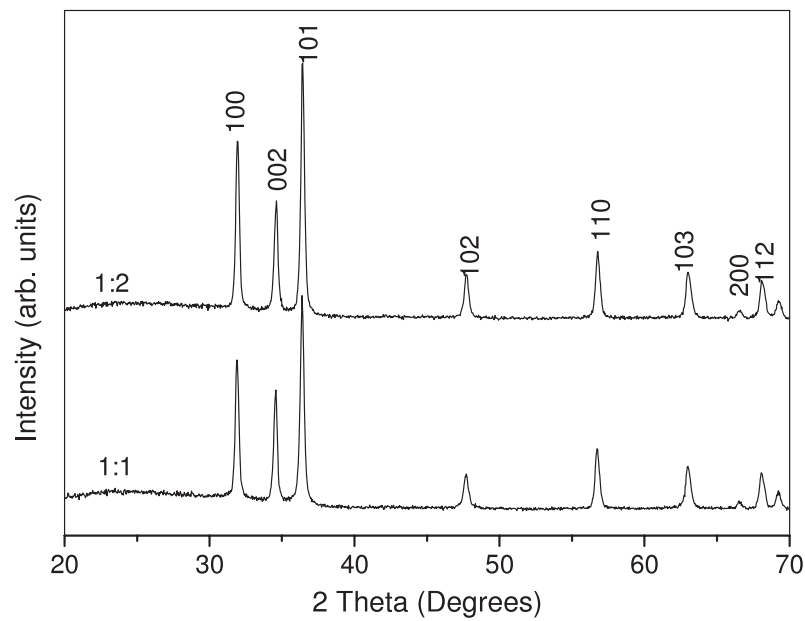

Figure 1. X-ray diffractograms for powders synthesized from 1:1 (lower) and 1:2 ratios of $\mathrm{Zn}\left(\mathrm{CH}_{3} \mathrm{CO}_{2}\right)_{2} \cdot 2 \mathrm{H}_{2} \mathrm{O}: \mathrm{C}_{6} \mathrm{H}_{4}-1,3-(\mathrm{COOH})_{2}$, calcined to $500{ }^{\circ} \mathrm{C}$.

on a Siemens D500 XRD, operating at $40 \mathrm{kV}$ and $30 \mathrm{~mA}$, at $25^{\circ} \mathrm{C}$, using $\mathrm{Cu} \mathrm{K} \alpha$ radiation. A Jeol J100CX TEM, operating at an accelerating voltage of $100 \mathrm{kV}$, and a Jeol 8600 SEM, operating accelerating voltages of $15 \mathrm{kV}$ and $7.5 \mathrm{kV}$, were used to image the powders. FT-IR spectra of the solid samples were undertaken in transmission mode between 4000 and $400 \mathrm{~cm}^{-1}$ using a Perkin-Elmer Spectrum GX microscope and potassium bromide diluent.

\section{Results and discussion}

Powder X-ray diffraction (XRD) patterns for powders synthesized in a ratio of zinc acetate to isophthalic acid of
$1: 1$ and $1: 2$, and calcined to $500^{\circ} \mathrm{C}$, are shown in figure 1 . These diffraction patterns correspond to the ISCD reference for polycrystalline zinc oxide [15], with no unidentified phases detected. XRD studies of the material synthesized reveals wurtzite $\mathrm{ZnO}$ has been produced in all cases. The domain sizes of the powders calcined to $500{ }^{\circ} \mathrm{C}$ was estimated from the (100) and (002) peaks to be $40 \pm 1 \mathrm{~nm}$ for powders synthesized in a 1:1 ratio of reagents, and $41 \pm 2 \mathrm{~nm}$ for the $1: 2$ powders. Equivalent studies for powders synthesized from an oxalic acid precursor showed domain sizes of the same or a slightly larger diameter $[4,5]$. The growth of domain sizes, indicated by peak sharpening, was observed for powders sintered to $800^{\circ} \mathrm{C}$; analysis of these samples revealed average domain diameters of $103 \pm 8 \mathrm{~nm}$ for powders synthesized in a 1:1 ratio, and $105 \pm 12 \mathrm{~nm}$ for particles synthesized in a 1:2 ratio.

Investigation of the powder morphology via electron microscopy revealed an unconventional aggregation, which can be seen in figure 2. Figures 2(a), (b) and (c) show SEM images of powders synthesized in a 1:1 and 1:2 ratio of reagents and calcined at $500{ }^{\circ} \mathrm{C}$, and in a $1: 1$ ratio calcined to $800^{\circ} \mathrm{C}$, respectively, at a magnification of $5000 \times$. It can be seen from these images that the decomposition of a precursor synthesized in a 1:1 ratio of reagents results in the production of micron scale aggregates, of uniform composition, while for the powders synthesized using twice the stoichiometric amount of isophthalic acid, some surfaces are smoother and brighter, possibly indicating the presence of an insulating material. Figure 2(d) shows a single grain, of the powder synthesized in a $1: 1$ ratio, calcined to $800^{\circ} \mathrm{C}$; a number of curved surfaces may be identified in this image. Figures $2(\mathrm{e})-(\mathrm{g})$ show TEM images of powders synthesized at a magnification of $20000 \times$. The planar aggregation of particles is visible in these images, as is the dramatic difference in morphology between particles sintered to $500^{\circ} \mathrm{C}$ and to $800^{\circ} \mathrm{C}$. While single flakes of
$1: 1500^{\circ} \mathrm{C}$
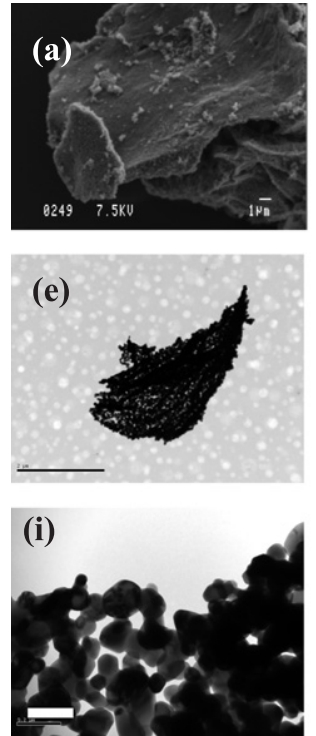

$1: 2500^{\circ} \mathrm{C}$

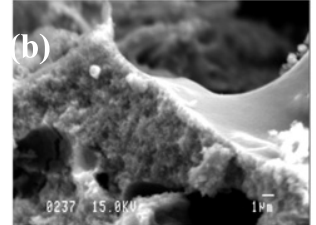

(f)
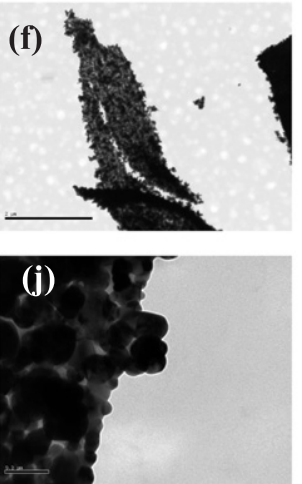

$1: 1800{ }^{\circ} \mathrm{C}$
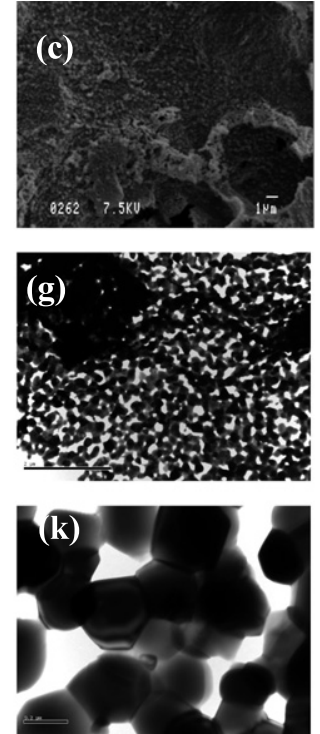

$1: 2800^{\circ} \mathrm{C}$
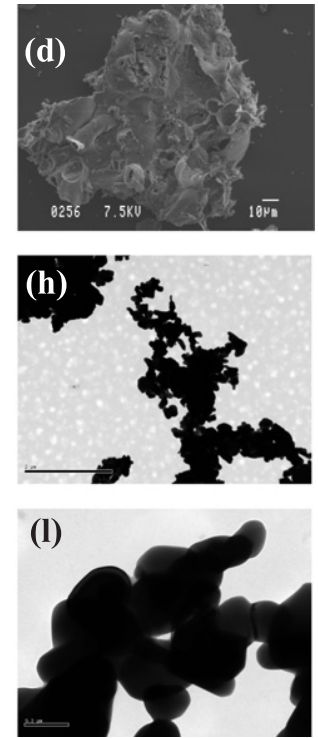

Figure 2. SEM (a)-(d) and TEM (e)-(l) images of product powders. Images (a), (e) and (i) show powders synthesized in a ratio of $\mathrm{Zn}\left(\mathrm{CH}_{3} \mathrm{CO}_{2}\right)_{2} \cdot 2 \mathrm{H}_{2} \mathrm{O}: \mathrm{C}_{6} \mathrm{H}_{4}-1,3-(\mathrm{COOH})_{2}$ of $1: 1$, and calcined to $500^{\circ} \mathrm{C} ;$, (b), (f) and (j), a precursor synthesized in the ratio $1: 2$, and calcined to $500{ }^{\circ} \mathrm{C}$; (c), (d), (g) and (k), $1: 1$ ratio, calcined to $800^{\circ} \mathrm{C}$; (h) and (l), a 1:2 ratio, calcined to $800^{\circ} \mathrm{C}$. Scale bars show: (a) $-(\mathrm{c}) 1 \mu \mathrm{m}$; (d) $10 \mu \mathrm{m}$; (e)-(h) $2 \mu \mathrm{m}$; (i)-(l) $200 \mathrm{~nm}$. 
A novel processing route for the production of nanoparticulate zinc oxide using an isophthalate precursor

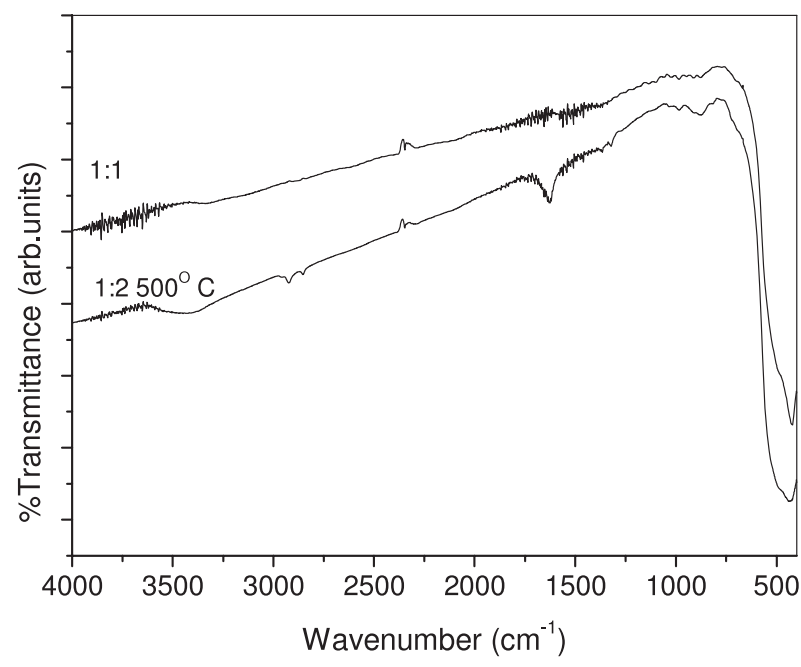

Figure 3. FT-IR spectra of powders synthesized in ratios of zinc acetate to isophthalic acid of $1: 1$ and $1: 2$ calcined to $500^{\circ} \mathrm{C}$.

the product material show a variation in contrast, and several small pores, the aggregate shown in figure $2(\mathrm{~g})$ is much larger, and contains pores of a greater size. This may be considered as the result of sintering of particles from a small number of planes to form a single flake, or an artefact of the preparation of TEM samples. For the material shown in figure 2(h), no planar structures were found in this sample, although a three-dimensional aggregation was also observed here. TEM images of these powders at a magnification of $100000 \times$ are shown in figures 2(i)-(1). For particles sintered to $500{ }^{\circ} \mathrm{C}$, the random aggregation of polydisperse particles is observed; those sintered to $800^{\circ} \mathrm{C}$ are shown to be less polydisperse but much larger, and less closely spaced. No grain boundaries are observed within discrete particles, indicating that the powders are composed of single crystal aggregates. Some variation on contrast is found for particles calcined to $500^{\circ} \mathrm{C}$, this may be attributed to surface impurities also noted for figure 2(b), since particles sintered to $800{ }^{\circ} \mathrm{C}$ show much less contrast variation. It is possible that the decomposition of surface ligands is not complete after calcination at the lower temperature. Particles synthesized in a 1:2 ratio of reagents are shown by TEM to be more closely packed than those synthesized in equimolar combinations; this could be a result of the number of singly bound surface ligands in this case, and their stronger interaction.

In order to identify the possible impurities in this material, FT-IR spectroscopy was performed on the samples; spectra of the powders calcined to $500{ }^{\circ} \mathrm{C}$ are shown in figure 3 . All three spectra shown here exhibit a strong, broad absorbance between 400 and $600 \mathrm{~cm}^{-1}$, as expected for a material that indexes so readily to zinc oxide. A number of weak absorbances are found at $875 \mathrm{~cm}^{-1}$; these are present in increasing strength as the amount of isophthalic acid used is increased above a stoichiometric ratio, and may thus indicate the increasing presence of a small amount of surface bound carboxyl groups here. Studies of an equivalent system, namely chelation with oxalic acid, have shown that the decomposition of organic ligands and production of zinc oxide occurs below the sintering temperature of zinc oxide; for the system investigated above, we have found that decomposition continues to occur to much higher temperatures, although a large amount of zinc oxide has formed at $500{ }^{\circ} \mathrm{C}$. Thus, while particles made from an isophthalate precursor are in close proximity, the organic residue present may prevent the contact of crystallite faces. On the removal of this residual layer, crystallites are in immediate contact at a temperature at which they can sinter. This may hinder the oriented aggregation expected for zinc oxide, and lead to the three-dimensional structure found in this case. The sintering of small particles may also account for the change in morphology found in these materials when calcined to $800^{\circ} \mathrm{C}$; since the aggregation structure of many of the larger particles will be fixed while the thermal energy allows the smaller ones to sinter, a porous network such as those seen in figure $2(\mathrm{~g})$ may be expected.

\section{Conclusions}

In conclusion, we have demonstrated the use of a dicarboxylic acid, namely isophthalic acid, for the processing of a porous zinc oxide network. Particles synthesized at $500^{\circ} \mathrm{C}$ are found to be slightly smaller than those synthesized through chelation with oxalic acid, and of a striking morphology. We have associated this characteristic structure with the presence of surface contaminants above the sintering temperature of zinc oxide when the isophthalate precursor is calcined. The nondirectional aggregation behaviour found may result in the presence of a higher number of exposed $c$ faces in the material, allowing greater catalytic and sensing activity for this material. Further investigation of the relationship between particle size and surface contamination, and calcination may yield the optimum conditions for such uses.

\section{References}

[1] El-Shobaky H G, Mokhtar M and El-Shobaky G A 1999 Appl. Catal. A 180335

[2] Glaspell G, Fuoco L and Samp El-Shall M 2005 J. Phys. Chem. B 10917350

[3] Bott B, Jones T A and Mann B 1984 Sensors Actuators 565

[4] Pillai S C, Kelly J M, McCormack D E and Ramesh R 2004 J. Mater. Chem. 141572

[5] Pillai S C, Kelly J M, McCormack D E, O'Brien P and Ramesh R 2003 J. Mater. Chem. 132586

[6] Nanto H, Minami T and Takata S J 1986 J. Appl. Phys. 60482

[7] Minami T 2000 MRS Bull. 2538

[8] Look D C 2001 Mater. Sci. Eng. B 80383

[9] Duffy G M, Pillai S C and McCormack D E 2007 J. Mater Chem. 17181

[10] Mondelaers D, Vanhoyland G, Van den Rul H, D'Haen J, van Bael M K, Mullens J and Van Puocke L C 2002 Mater. Res. Bull. 37901

[11] Pechini P M 1967 US Patent Specification 3330697

[12] Kanade K G, Kale B B, Aiyer R C and Das B K 2006 Mater Res. Bull. 41590

[13] Wu L, Wu Y and Lu Y 2006 Mater. Res. Bull. 41128

[14] Zhou Y-F, Zhao Y-J, Sun D-F, Weng J-B, Cao R and Hung M-C 2003 Polyhedron 221231

[15] Powder Diffraction File PDF\#00-036-1451 